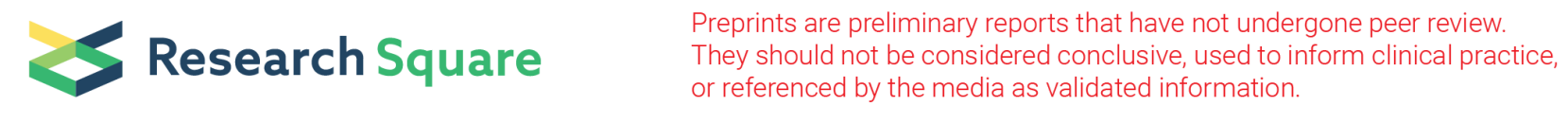

\title{
Clinical Efficacy of Sodium-Glucose Co-Transporter-2 (SGLT2) Inhibitor in Cardiovascular Outcomes Among Patients with and Without Heart Failure: A Systematic Review and Meta-Analysis
}

\author{
Mei-Chuan Lee \\ Chi Mei Foundation Hospital: Chi Mei Medical Center \\ Yi-Ming Hua \\ Chi Mei Medical Center \\ Chun-Ting Yang \\ National Cheng Kung University \\ Wei-Ting Chang \\ Chi Mei Medical Center \\ Fang-Hsiu Kuo \\ Chi Mei Medical Center \\ Hsin-Ju Tang \\ Chi Mei Medical Center \\ Han Siong Toh \\ Chi Mei Medical Center \\ Tsung Yu \\ National Cheng Kung University \\ Carol Strong \\ National Cheng Kung University \\ Hung-Yu Chang \\ Cheng Hsin General Hospital \\ Chia-Te Liao ( $\nabla$ drctliao@gmail.com ) \\ Chi Mei Foundation Hospital: Chi Mei Medical Center
}

Original investigation

Keywords: sodium-glucose co-transporter-2 inhibitor, SGLT2 inhibitor, heart failure, cardiovascular outcomes, hospitalization for heart failure, SGLT2/SGLT1 selectivity

Posted Date: June 9th, 2021

DOl: https://doi.org/10.21203/rs.3.rs-586027/v1

License: (1) This work is licensed under a Creative Commons Attribution 4.0 International License. Read Full License 


\section{Abstract}

Background

Heart failure (HF) has become a healthcare challenge worldwide. Recently, certain trials on sodium-glucose co-transporter-2 (SGLT2) inhibitor showed benefits for patients with HF. This study aimed to systematically review the literature and investigate the clinical efficacy of SGLT2 inhibitors in cardiovascular events among patients with and without HF.

Methods

We searched randomized controlled trials (RCTs) in PubMed, Cochrane databases, Embase, and ClinicalTrials.gov registry form inception to October 2020. Dichotomous variables were pooled using a random-effects model and presented with a risk ratio (RR) and $95 \%$ confidence interval (Cl). Subgroup metaanalyses were carried out by high/low SGLT2/SGLT1 selectivity and individual SGLT2 inhibitor.

Results

A total of 10 RCTs comprised of 52,607 patients were eligible for the analyses. SGLT2 inhibitors reduced the risk of total cardiovascular death or hospitalization for HF (RR 0.79, [95\% Cl: 0.74 to 0.84 ]; $p<0.01, P=31 \%$ ). Apart from stroke, SGLT2 inhibitors contributed to a risk reduction in major adverse cardiovascular events (MACE, RR 0.93, [95\% Cl: 0.88 to 0.99]; $p=0.03, P=0$ ), all-cause mortality (RR $0.92,[95 \% \mathrm{Cl}: 0.85$ to 0.99$] ; p=0.03, P=0$ ), cardiovascular death (RR 0.91, [95\% Cl: 0.83 to 0.99 ]; $p=0.03, P=0$ ), hospitalization for HF (RR 0.72 , [95\% Cl: 0.66 to 0.79 ]; $p<0.01, P=0$ ), and myocardial infarction (RR 0.89, [95\% Cl: 0.80 to 0.99 ]; $p=0.03, P=0$ ). For HF patients, SGLT2 inhibitors had more clinical benefits in terms of all-cause mortality and cardiovascular death, while advantages were observed in MACE and myocardial infarction for non-HF patients. Furthermore, SGLT2 inhibitors with low SGLT2/SGLT1 selectivity have better efficacy for hospitalization of HF, compared with high-selectivity inhibitors (RR 0.51 [95\% Cl: $0.35-0.75$ ] versus 0.73 [95\% Cl: 0.66-0.81] for HF patients).

Conclusions

SGLT2 inhibitors significantly mitigate hospitalization for HF. Between HF and non-HF populations, this regimen reduce mortality for HF patients and improve MACE and myocardial infarction for non-HF patients. The SGLT2 inhibitor, mixed with the effect of SGLT1 inhibitors, may lead to a lower risk of hospitalization for HF.

\section{Introduction}

Heart failure (HF) is the final manifestation of the most cardiovascular diseases. ${ }^{1}$ Globally, an estimated $1-2 \%$ of the population have $\mathrm{HF}$, and the prevalence continues to grow due to an aging society. ${ }^{2}$ Due to the increasing prevalence, and a high risk of hospitalization, disability and mortality, HF has become a heavy burden on healthcare systems worldwide during the past decades.

Current treatment for HF is based on the existing evidence and mostly limited to patients with $\mathrm{HF}$ and reduced ejection fraction (HFrEF). The main management of HFrEF is to reduce the mortality and hospitalization for HF, and the pharmacological strategies rely on neurohormonal blockades, i.e., angiotensin converting enzyme inhibitors (ACEI), angiotensin receptor blockers (ARB) or angiotensin receptor-neprilysin inhibitor (ARNI), beta-blockers and mineralocorticoid receptor antagonists. ${ }^{3,4}$ However, these medical therapies are usually used in selected conditions and the following adverse effects, like worsened renal function, hyperkalemia, and hypotension, may disrupt the management. More medical therapies with different mechanisms are still needed for HF management.

Sodium-glucose co-transporter 2 (SGLT2) inhibitors have been recommended in patients with type 2 diabetes to control blood sugar by increasing urinary excretion of glucose. ${ }^{5}$ Currently, in addition to patients with type 2 diabetes, ${ }^{6-8}$ some large-scale randomized controlled trials (RCTs) of SGLT2 inhibitors have shown its clinical efficacy in patients with HF, i.e., the DAPA-HF (Dapagliflozin and Prevention of Adverse-Outcomes in Heart Failure) trial, EMPEROR-Reduced (EMPagliflozin outcomE tRial in Patients With chrOnic heaRt Failure With Reduced Ejection Fraction) trial, and SOLOIST-WHF (Effect of Sotagliflozin on Cardiovascular Events in Patients With Type 2 Diabetes Post Worsening Heart Failure) trial. ${ }^{9-11}$ Although the three trials provided evaluations of SGLT2 inhibitors for patients with HF, the results were heterogeneous and may not accurately represent the cardiovascular benefits for SGLT2 inhibitors comprehensively. The previous meta-analyses of SGLT2 inhibitors either did not focus on the patients with HF across the trials, ${ }^{12-16}$ or not comprehensively review all RCTs of SLGT2 inhibitors. ${ }^{17-20}$ Therefore, we aimed to perform an updated systematic review and meta-analysis to compare the clinical efficacy of SGLT2 inhibitors in patients with and without HF.

\section{Materials And Methods}

\section{Inclusion criteria}

The current study included RCTs evaluating the effect of SGLT2 inhibitors on reducing risks of cardiovascular death or hospitalization for HF. Patients were enrolled irrespective of the presence or absence of HF. Additionally, the identified studies were required to have a clear report of the inclusion and exclusion criteria. The following studies were excluded: (1) observational studies, (2) duplicate studies, (3) studies with a lack of cardiovascular outcomes (4) nonEnglish articles, (5) studies including only a protocol, and (6) animal data. 
Relevant studies published up until October 2020 were identified from PubMed, Cochrane databases and Embase. Unpublished studies were collected from the ClinicalTrials.gov registry (http://clinicaltrials.gov/). The following keywords were used: heart failure, heart right ventricle failure, congenital heart disease, sodium glucose cotransporter 2 inhibitor*, sodium glucose cotransporter-2 inhibitor*, sodium-glucose co-transporter-2 inhibitor*, sodium-glucose cotransporter 2 inhibitor*, sodium-glucose cotransporter-2 inhibitor*, sodium glucose cotransporter inhibitor*, sodium glucose cotransporter inhibitor*, sodium-glucose cotransporter inhibitor*, sodium-glucose cotransporter inhibitor*, sodium-glucose cotransporter inhibitor*, SGLT-2 inhibitor*, SGLT2 inhibitor*, empagliflozin, dapagliflozin, canagliflozin, ertugliflozin, ipragliflozin, luseogliflozin and sotagliflozin. All retrieved abstracts, studies, and citations were reviewed. In addition, we identified the other studies by using the reference sections of relevant papers and by corresponding with subject experts.

\section{Data extraction}

Baseline and outcome data were independently extracted by two reviewers (YMH and MCL). The study design, subject characteristics, comorbidity, comedication, regimen of SGLT2 inhibitors and the numbers of cardiovascular deaths or hospitalizations for HF were extracted. Disagreements were resolved by discussion with another author (CTL).

\section{Methodological quality appraisal}

Two reviewers (YMH and $\mathrm{MCL}$ ) independently assessed the methodological quality of each study by using the risk of bias method recommended by Cochrane Collaboration. ${ }^{21}$ Several domains were assessed, including the adequacy of randomization, concealment of allocation, blinding of patients and outcome assessors, length of follow-up, information provided to patients regarding study withdrawals, whether intention-to-treat analysis was performed, and freedom from other biases.

The primary endpoint was the incidence of cardiovascular death or hospitalization for HF. The secondary outcomes were the composite of major adverse cardiovascular events (MACE), including cardiovascular death, myocardial infarction, or ischemic stroke, and the individual cardiovascular events, i.e., allcause mortality, cardiovascular death, hospitalization for HF, myocardial infarction and ischemic stroke.

\section{Statistical analyses}

Data were input and analyzed using Review Manager version 5.4 (The Cochrane Collaboration, Oxford, England). A meta-analysis was performed in concordance with the PRISMA guidelines. ${ }^{22}$ Standard deviations were estimated from the provided confidence interval (CI) limits or standard error. Furthermore, dichotomous outcomes were analyzed using a risk ratio (RR) as the summary statistics. The precision levels of the effect sizes were reported as $95 \%$ Cls. A pooled estimate of the RR and weighted mean difference was computed using the DerSimonian and Laird random effects model. ${ }^{23}$

We used Cochrane $Q$ tests and $R$ statistics to evaluate the statistical heterogeneity and inconsistency of treatment effects across the studies. The statistical significance was set at $p<0.10$ for Cochrane $\mathrm{Q}$ tests. Statistical heterogeneity was assessed using the $R^{2}$ statistics to quantify the proportion of the total outcome variability across the studies. According to the different values of $R$, the heterogeneity across the trials was considered to be low $(R \leq 25 \%)$, moderate $\left(25 \%<R^{2}<75 \%\right)$, and high $\left(R^{2} \geq 75 \%\right)$. Given an $R^{2}$ value of greater than $50 \%$, a further sensitivity analysis was performed to evaluate the uncertainty of the results. A subgroup analysis was used to assess the individual effects across different SGLT2 inhibitors. Furthermore, the subgroup analysis also compared medications with high and low SGLT2/SGLT1 selectivity. High SGLT2/SGLT1 selectivity included dapagliflozin, empagliflozin and ertugliflozin, while low SGLT2/SGLT1 selectivity (dual SGLT2/1 inhibitors) included canagliflozin and sotagliflozin. ${ }^{24}$

\section{Results}

Search results and eligible studies

The preferred reporting items for systematic reviews and meta-analyses are presented in the (PRISMA) flowchart in Figure 1. The initial search strategy yielded 2,152 studies. After removing duplicates, the title and abstract of the 1,503 identified studies were screened. We excluded 1,264 articles which were not RCTs or did not match the search strategy. Subsequently, 34 articles were excluded due to the unavailability of full-text and published data, or withdrawal from ClinicalTrials.gov. Then, we retrieved 205 studies, of which 195 were excluded after the full-texts assessed. (Figure 1) Finally, 10 RCTs with qualitative synthesis of complete data were included for the current meta-analyses. ${ }^{6-11,25-28}$

\section{Characteristics of the studies and populations included}

The 10 included RCTs evaluated the effects of five SGLT2 inhibitors, canagliflozin (the CANVAS PROGRAM trial), ${ }^{6}$ dapagliflozin (the DEFINE-HF trial, the DECLARE-TIMI 58 trial, and the DAPA-HF trial), 8,9,25 empagliflozin (the EMPA-RESPONSE-AHF trial, the EMPA-REG OUTCOME trial, and the EMPEROR-Reduced trial), ${ }^{7,10,26}$ sotagliflozin (the SOLOIST-WHF trial and SCORED trial), ${ }^{11,28}$ and ertugliflozin (the VERTIS-CV trial). ${ }^{27}$

A total of 52,607 patients were included in the meta-analysis. The mean age of the patients with EMPA-RESPONSE-AHF was the highest (79 years old in the empagliflozin group; 73 years old in the placebo group), while the DEFINE-HF patients were the youngest (on average 62 years old in the dapagliflozin group; 60 years old in the placebo group). The DECLARE-TIMI 58 trial had the longest follow-up period at 4.2 years, ${ }^{8}$ and the EMPA-RESPONSE-AHF had the shortest follow-up period at only 12 weeks. ${ }^{26}$ (Table 1 and Supplementary Table 1 ).

The CANVAS PROGRAM, DECLARE-TIMI 58, SCORED, VERTIS-CV, and EMPA-REG OUTCOME trials included patients irrespective of the presence or absence of HF, while the DEFINE-HF, EMPA-RESPONSE-AHF, EMPEROR-Reduced, SOLOIST-WHF, and DAPA-HF trials only focused on patients with HF. In the meta-analysis, data from the above eight studies were pooled to compare the total number of cardiovascular deaths or hospitalizations for HF of SGLT2 inhibitors versus placebo in patients with and without HF. 
Risk of bias assessment

Supplementary Figure 1 and Figure 2 show the results of quality assessment.

In addition to the DECLARE-TIMI 58 and DEFINE-HF trial, eight of the included studies had a low risk of bias with adequate randomization, sequence descriptions, and allocation concealment. Blinding for the participants was carried out in all studies but six studies did not explicitly describe the blinding for assessors. All studies had low rates of lost to follow-up, and they all used intention-to-treat analysis and had available protocols.

\section{Meta-analyses of primary outcomes}

Figure 2 shows the primary endpoint, i.e., the composite of cardiovascular deaths and hospitalizations for HF. The risk of a primary endpoint event was $7.23 \%$ $(2,510 / 34,699)$ in the SGLT2 inhibitors group and $9.35 \%(2,633 / 28,149)$ in the placebo group, respectively. SGLT2 inhibitors significantly reduced the risk of total cardiovascular death or hospitalization for HF by $21 \%$ (RR $0.79,[95 \% \mathrm{Cl}: 0.74$ to 0.84$] ; p<0.001, P=31 \%$ ). In addition, the individual risk reduction for patients with $\mathrm{HF}$ was $24 \%$ (RR 0.76 , [95\% Cl: 0.72 to 0.81 ]; $p<0.001, P^{2}=0 \%$ ), and that for patients with non-HF was $17 \%$ (RR $0.83,[95 \% \mathrm{Cl}: 0.72$ to 0.95 ]; $p=$ $0.006, P=49 \%)$.

\section{Meta-analyses of secondary outcomes}

Figure 3 and 4 show the results of the secondary endpoints, MACE, all-cause death, cardiovascular death, hospitalization for HF, myocardial infarction and stroke from the eligible trials.

In the SGLT2 inhibitors group, 9.77\% of the patients $(1,952 / 19,960)$ had MACE and $10.21 \%(1,601 / 15,670)$ in the placebo group. SGLT2 inhibitors reduced the risk of MACE by $7 \%$ (RR $0.93,[95 \% \mathrm{Cl}: 0.88$ to 0.99 ]; $p=0.03, P=0 \%$ ). However, SGLT2 inhibitors did not significantly reduce the risk of MACE in patients with $\mathrm{HF}(\mathrm{RR} 0.98,[95 \% \mathrm{Cl}: 0.85$ to 1.14 ]; $p=0.81, P=24 \%$ ), while it resulted in a significant reduction for patients without $\mathrm{HF}$ (RR 0.92 , [95\% $\mathrm{Cl}: 0.85$ to 0.99 ]; $p=$ $0.02, P=0 \%)$. (Figure $3 \mathrm{~A})$

The all-cause mortality risk for patients using SGLT2 inhibitors was 7.05\% $(1,200 / 17,019)$ and 7.80\% $(1,216 / 15,578)$ for the placebo group. SGLT2 inhibitors significantly reduced the overall mortality by $8 \%$ (RR 0.92 , [95\% Cl: 0.85 to 0.99 ]; $p=0.03, P=0 \%$ ). In HF patients, SGLT2 inhibitors caused a significant risk reduction for all-cause mortality (RR 0.89 , [95\% Cl: 0.80 to 0.99 ]; $p=0.04, R=0 \%$ ), while the effect was absent for non-HF patients (RR 0.94 , [95\% Cl: 0.85 to 1.05]; $p=0.26, l^{2}=0 \%$ ). (Figure 3B)

The number of cardiovascular deaths was 953 , comprised of $4.92 \%(953 / 19,352)$ in the SGLT2 inhibitors group, and 5.51\% (985/17,889) in the placebo group. In comparison, SGLT2 inhibitors significantly decreased the risk of cardiovascular death (RR $0.91,[95 \% \mathrm{Cl}: 0.83$ to 0.99 ]; $p=0.03, P=0 \%$ ). The risk of cardiovascular death in HF patients was significantly reduced by SGLT2 inhibitors (RR $0.88,[95 \% \mathrm{Cl}: 0.79$ to 0.97 ]; $p=0.01, P=0 \%$ ), but the reduction was insignificant in non-HF patients (RR 0.98, [95\% Cl: 0.84 to 1.14$] ; p=0.77,2=0 \%$ ). (Figure $4 \mathrm{~A}$ )

The risk of hospitalization for HF was $4.36 \%(819 / 18,784)$ for patients using SGLT2 inhibitors and $6.34 \%(1,099 / 17,334)$ for those not using SGLT2 inhibitors. SGLT2 inhibitors significantly reduced the risk of hospitalization for HF (RR 0.72 , [95\% Cl: 0.66 to 0.79 ]; $p<0.001, P=0 \%$ ). The risk reduction due to SGLT2 inhibitors was significant in both $\mathrm{HF}$ ( $\mathrm{RR} 0.72$, [95\% Cl: 0.64 to 0.80 ]; $p<0.001, R=8 \%$ ) and non-HF patients ( $\mathrm{RR} 0.74,[95 \% \mathrm{Cl}: 0.61$ to 0.89 ]; $p=0.001, P=0 \%$ ). (Figure 4B)

The risk of myocardial infarction in patients using SGLT2 inhibitors was 4.30\% (624/14,508), and 4.89\% in the placebo group (639/13,057). The risk of myocardial infarction was significantly reduced by $11 \%$ (RR 0.89 , [95\% Cl: 0.80 to 0.99 ]; $p=0.03, P=0 \%$ ). For patients with $\mathrm{HF}$, SGLT2 inhibitors did not contribute to a significant risk reduction in myocardial infarction (RR $0.95,[95 \% \mathrm{Cl}: 0.65$ to 1.39$] ; p=0.79, P=30 \%$ ), but there was a significant reduction for patients without HF (RR 0.88, [95\% Cl: 0.78 to 0.99$] ; p=0.03, P=0 \%$ ). (Figure $4 \mathrm{C}$ )

The risk of stroke was $2.76 \%(401 / 14,508)$ for the SGLT2 inhibitors group and $2.93 \%(382 / 13,057)$ for placebo group. SGLT2 inhibitors did not significantly lower the risk of stroke (RR 0.94, [95\% Cl: 0.82 to 1.08]; $p=0.37, P=0 \%$ ). Likewise, SGLT2 inhibitors did not cause a significant risk reduction in stroke irrespective of the presence or absence of HF. (for HF patients, RR 0.95, [95\% Cl: 0.67 to 1.36$] ; p=0.80, P=12 \%$; for non-HF patients, RR 0.93 , [95\% Cl: 0.80 to 1.09]; $p=0.39, R^{2}=0 \%$ ). (Figure 4D)

\section{Subgroup analysis}

In the subgroup analysis, dapagliflozin, empagliflozin, canagliflozin and sotagliflozin significantly reduced the risk of cardiovascular death or hospitalization for HF in patients with HF. In patients without HF, only dapagliflozin and empagliflozin resulted in a significant risk reduction. (Table 2)

In terms of cardiovascular death, no individual SGLT2 inhibitor showed a significant risk reduction for both HF and non-HF patients. Regarding hospitalization for HF, dapagliflozin, empagliflozin and canagliflozin showed a significant risk reduction for patients with HF, while only dapagliflozin and canagliflozin showed evidence to support the risk reduction for patients without HF.

Both high and low SGLT2/SGLT1 selectivity inhibitors significantly reduced the risk of cardiovascular death or hospitalization for HF in HF patients (RR 0.79 , [95\% Cl: 0.74 to 0.85 ]; $p<0.05, P=0 \%$ for high SGLT2/SGLT1 selectivity; RR 0.69, [95\% Cl: 0.62 to 0.77 ]; $p<0.05, P^{2}=0 \%$ for low SGLT2/SGLT1 selectivity); particularly, they resulted in a significant risk reduction in hospitalization for HF. (Table 2) Notably, for non-HF patients, only high SGLT2/SGLT1 selectivity inhibitors contributed to a significantly reduced risk of hospitalization for $\mathrm{HF}$ ( RR 0.81 [0.66-0.99], $p<0.05, P=71 \%$ ). (Table 2)

Page $4 / 13$ 


\section{Discussion}

In the current systematic review and meta-analysis including 52,607 patients, SGLT2 inhibitors reduced the risks of cardiovascular death, hospitalization for HF, MACE, all-cause mortality, and myocardial infarction, but the clinical benefit was not observed in the prevention of ischemic stroke. For non-HF patients, SGLT2 inhibitors lowered the risk of hospitalization for HF, MACE, and myocardial infarction. For those with HF, using SGLT2 inhibitors contributes to a lower risk of hospitalization for HF, cardiovascular death, and all-cause death.

The previous RCTs and meta-analysis demonstrated that SGLT2 inhibitors have significant benefits in reducing hospitalization for HF, cardiovascular events and mortality in patients with type 2 diabetes. ${ }^{6-8,13,28}$ Furthermore, among the patients, those with higher risks of cardiovascular disease or heart failure may obtain more clinical benefits by using SGLT2 inhibitors. ${ }^{29,30}$ Recently, there have been three large-scale HF-specific RCTs on SGLT2 inhibitors in HF patients (DAPA-HF, EMPA-Reduced, and SOLOIST-WHF trial). ${ }^{9-11}$ Despite the diversity across the three trials, i.e., different severities of HF and renal impairment, concomitant diabetes, or the selectivity of SGLT2 and SGLT1 inhibition, the clinical efficacy in the composite outcomes of hospitalization for HF or cardiovascular death proved to be beneficial for HF populations. Our meta-analysis results showed consistent findings for SGLT2 inhibitors with a $24 \%$ reduction in composite outcomes among patients with HF. Even for individual events, SGLT2 inhibitors reduced the risk of hospitalization and cardiovascular death by $28 \%$ and $12 \%$, respectively.

On the other hand, the efficacy of SGLT2 inhibitors with regards to mortality remains debatable. In the three HF-specific trials, only the DAPA-HF trial demonstrated a marked improvement in cardiovascular and all-cause mortality, while the EMPA-Reduced and SOLOIST-WHF trials did not. The previous metaanalysis, including only the DAPA-HF and EMPA-Reduced trials reported that SGLT2 inhibitors significantly reduced the risk of cardiovascular and all-cause death for HF patients. ${ }^{17}$ Our findings also showed that SGLT2 inhibitors caused a significant risk reduction in cardiovascular and all-cause mortality for HF patients. Notably, the clinical benefits in terms of death were merely observed in patients with HF; the benefits in non-HF patients were not significant.

Nevertheless, our subgroup analysis found that SGLT2 inhibitor alone did not result in a significant risk reduction in cardiovascular and all-cause death regardless of the presence of HF. (Table 2) Therefore, to conclude that a specific SGLT2 inhibitor has significant clinical efficacy in terms of mortality, would be an overstatement. More future clinical studies and real-world data are warranted to assess the efficacy of SGLT2 inhibitors.

Sodium-glucose co-transporters can be classified by the modulatory site. SGLT1 is the primary transporter which uptakes dietary glucose and galactose in the intestine, while SGLT2 reuptakes $90 \%$ of filtered glucose in the tubular system of the kidney. ${ }^{31}$ The various SGLT inhibitors have different characteristics, including structure, selectivity, pharmacokinetics, efficacy, and safety, according to their modulatory sites. ${ }^{32}$ Among the above medications, dapagliflozin, empagliflozin and ertugliflozin are classified as inhibitors with high SGLT2/SGLT1 selectivity, while canagliflozin and sotagliflozin belong to low SGLT2/SGLT1 selectivity. ${ }^{24}$ In our findings, SGLT2 inhibitors with low SGLT2/SGLT1 selectivity reduced the risk of total cardiovascular death or hospitalization for HF in HF patients to a larger extent compared to SGLT2 inhibitors with high SGLT2/SGLT1 selectivity (RR 0.69 for low selectivity versus 0.79 for high selectivity). Likewise, the low SGLT2/SGLT1-selectivity inhibitors showed a lower risk of hospitalization for HF than the high-selectivity inhibitors for HF patients. Nevertheless, the phenomenon was not observed in non-HF patients. Previous studies have shown that SGLT1 protein expression was detected in myocardial cells instead of SGLT2 proteins, and the modulation by SGLT1 inhibitors contributes to clinical benefits in left ventricle remodeling and systolic function for HF patients. ${ }^{33,34}$ This may be a plausible explanation for why low SGLT2/SGLT1-selectivity inhibitors bring more cardiovascular benefits for HF patients than non-HF patients. Further studies are needed to investigate the hypothesis.

Some limitations should be noted in our study. First, due to a lack of individual-level data from the identified studies, differences in the severities of HF, left ventricular ejection fractions, percentages of males and females, varied background therapies, and safety outcomes, may limit the interpretation of our findings. The follow-up period, for instance, also varied in each study, and the follow-up periods for the DEFINE-HF and EMPA-RESPONSE-AHF trials were only 13- and 12-weeks, respectively. Cardiovascular events may not occur during this short period, which may lead to concerns about the overestimation of clinical benefits of SGLT2 inhibitors. However, the issue may not alter the main outcomes due to the small sample size in both trials. Besides, the random-effect model was used in the statistical calculations to account for the methodological heterogeneity and the main results with low ${ }^{2}$ values support the robustness of the interpretations. Second, in our subgroup analysis, only one RCT was conducted for some SGLT2 inhibitors i.e., canagliflozin, ertugliflozin and empagliflozin, and sotagliflozin lacked complete primary outcomes (Table 2). This may reduce statistical power when interpreting the clinical efficacy. Further post-hoc analyses or RCTs for the SGLT2 inhibitors will be needed. Third, although five out of the 10 RCTs focused on HF patients, and three trials, the DAPA-HF, EMPEROR-Reduced and SOLOIST-WHF trials, had large sample sizes, the heterogeneity in the primary outcomes was low, and inferences for each SGLT2 inhibitor should be made with caution.

\section{Conclusions}

This meta-analysis, including 52,607 patients, compared the clinical efficacy of SGLT2 inhibitors between patients with and without HF. SGLT2 inhibitors significantly reduced hospitalization for HF and had little effect on stroke prevention irrespective of the presence or absence of HF. For patients with HF, SGLT2 inhibitors mitigate the risk of death, while the regimen has better efficacy in improving MACE and myocardial infarction for those without HF. Furthermore, the SGLT2 inhibitor, mixed with the effect of SGLT1 inhibitors, may lead to a lower risk of hospitalization for HF, compared to SGLT2 inhibitors alone. The above findings reinforce the clinical benefits of SGLT2 inhibitors for patients with or without HF. Further studies may be warranted to compare high and low SGLT2/SGLT1-selectivity SGLT2 inhibitors.

\section{Abbreviations}

Heart failure (HF) 
Heart failure and reduced ejection fraction (HFrEF)

Angiotensin converting enzyme inhibitors (ACEI)

Angiotensin receptor blockers (ARB)

Angiotensin receptor-neprilysin inhibitor (ARNI)

Sodium-glucose co-transporter 2 (SGLT2)

Randomized controlled trials (RCTs)

Major adverse cardiovascular events (MACE)

Confidence interval (Cl)

Risk ratio (RR)

\section{Declarations}

Ethics approval and consent to participate

Not applicable

Consent for publication

Not applicable

Availability of data and materials

Not applicable

Competing interests

The authors declare that they have no competing interests

Funding

None

Authors' contributions

MCL and YMH had an equal contribution to this study, including the conception and design of the work, and drafting of the manuscript. CTY, WTC, FHK, HJT and CTL contributed to the acquisition, analysis, and interpretation of data for this work. HST, TY, CS, HYC and CTL critically revised the manuscript.

Acknowledgements

Not applicable

\section{References}

1. Kemp CD, Conte JV. The pathophysiology of heart failure. Cardiovasc Pathol. 2012 Sep-0ct;21(5):365-71.

2. Braunwald $\mathrm{E}$. The war against heart failure: the Lancet lecture. Lancet. 2015 Feb 28;385(9970):812-24.

3. Yancy CW, Jessup M, Bozkurt B, Butler J, Casey DE Jr, Colvin MM, Drazner MH, Filippatos GS, Fonarow GC, Givertz MM, Hollenberg SM, Lindenfeld J, Masoudi FA, McBride PE, Peterson PN, Stevenson LW, Westlake C. 2017 ACC/AHA/HFSA Focused Update of the 2013 ACCF/AHA Guideline for the Management of Heart Failure: A Report of the American College of Cardiology/American Heart Association Task Force on Clinical Practice Guidelines and the Heart Failure Society of America. J Am Coll Cardiol. 2017 Aug 8;70(6):776-803.

4. Ponikowski P, Voors AA, Anker SD, Bueno H, Cleland JGF, Coats AJS, Falk V, González-Juanatey JR, Harjola VP, Jankowska EA, Jessup M, Linde C, Nihoyannopoulos P, Parissis JT, Pieske B, Riley JP, Rosano GMC, Ruilope LM, Ruschitzka F, Rutten FH, van der Meer P; ESC Scientific Document Group. 2016 ESC Guidelines for the diagnosis and treatment of acute and chronic heart failure: The Task Force for the diagnosis and treatment of acute and chronic heart failure of the European Society of Cardiology (ESC)Developed with the special contribution of the Heart Failure Association (HFA) of the ESC. Eur Heart J. 2016 Jul 14;37(27):2129-2200.

5. Navaneethan SD, Zoungas S, Caramori ML, Chan JCN, Heerspink HJL, Hurst C, Liew A, Michos ED, Olowu WA, Sadusky T, Tandon N, Tuttle KR, Wanner C, Wilkens KG, Lytvyn L, Craig JC, Tunnicliffe DJ, Howell M, Tonelli M, Cheung M, Earley A, Rossing P, de Boer IH, Khunti K. Diabetes Management in Chronic Kidney Disease: Synopsis of the 2020 KDIGO Clinical Practice Guideline. Ann Intern Med. 2021 Mar;174(3):385-394.

6. Neal B, Perkovic V, Mahaffey KW, de Zeeuw D, Fulcher G, Erondu N, Shaw W, Law G, Desai M, Matthews DR; CANVAS Program Collaborative Group. Canagliflozin and Cardiovascular and Renal Events in Type 2 Diabetes. N Engl J Med. 2017 Aug 17;377(7):644-657. 
7. Zinman B, Wanner C, Lachin JM, Fitchett D, Bluhmki E, Hantel S, Mattheus M, Devins T, Johansen OE, Woerle HJ, Broedl UC, Inzucchi SE; EMPA-REG OUTCOME Investigators. Empagliflozin, Cardiovascular Outcomes, and Mortality in Type 2 Diabetes. N Engl J Med. 2015 Nov 26;373(22):2117-28.

8. Wiviott SD, Raz I, Bonaca MP, Mosenzon O, Kato ET, Cahn A, Silverman MG, Zelniker TA, Kuder JF, Murphy SA, Bhatt DL, Leiter LA, McGuire DK, Wilding JPH, Ruff CT, Gause-Nilsson IAM, Fredriksson M, Johansson PA, Langkilde AM, Sabatine MS; DECLARE-TIMI 58 Investigators. Dapagliflozin and Cardiovascular Outcomes in Type 2 Diabetes. N Engl J Med. 2019 Jan 24;380(4):347-357.

9. McMurray JJV, Solomon SD, Inzucchi SE, Køber L, Kosiborod MN, Martinez FA, Ponikowski P, Sabatine MS, Anand IS, Bělohlávek J, Böhm M, Chiang CE, Chopra VK, de Boer RA, Desai AS, Diez M, Drozdz J, Dukát A, Ge J, Howlett JG, Katova T, Kitakaze M, Ljungman CEA, Merkely B, Nicolau JC, O'Meara E, Petrie MC, Vinh PN, Schou M, Tereshchenko S, Verma S, Held C, DeMets DL, Docherty KF, Jhund PS, Bengtsson O, Sjöstrand M, Langkilde AM; DAPA-HF Trial Committees and Investigators. Dapagliflozin in Patients with Heart Failure and Reduced Ejection Fraction. N Engl J Med. 2019 Nov 21;381(21):19952008.

10. Packer M, Anker SD, Butler J, Filippatos G, Pocock SJ, Carson P, Januzzi J, Verma S, Tsutsui H, Brueckmann M, Jamal W, Kimura K, Schnee J, Zeller C, Cotton D, Bocchi E, Böhm M, Choi DJ, Chopra V, Chuquiure E, Giannetti N, Janssens S, Zhang J, Gonzalez Juanatey JR, Kaul S, Brunner-La Rocca HP, Merkely B, Nicholls SJ, Perrone S, Pina I, Ponikowski P, Sattar N, Senni M, Seronde MF, Spinar J, Squire I, Taddei S, Wanner C, Zannad F; EMPERORReduced Trial Investigators. Cardiovascular and Renal Outcomes with Empagliflozin in Heart Failure. N Engl J Med. 2020 Oct 8;383(15):1413-1424.

11. Bhatt DL, Szarek M, Steg PG, Cannon CP, Leiter LA, McGuire DK, Lewis JB, Riddle MC, Voors AA, Metra M, Lund LH, Komajda M, Testani JM, Wilcox CS, Ponikowski P, Lopes RD, Verma S, Lapuerta P, Pitt B; SOLOIST-WHF Trial Investigators. Sotagliflozin in Patients with Diabetes and Recent Worsening Heart Failure. N Engl J Med. 2021 Jan 14;384(2):117-128.

12. Yamani N, Usman MS, Akhtar T, Fatima K, Asmi N, Khan MS. Sodium-glucose co-transporter 2 inhibitors for the prevention of heart failure in type 2 diabetes: A systematic review and meta-analysis. Eur J Prev Cardiol. 2020 Apr;27(6):667-670.

13. Zelniker TA, Wiviott SD, Raz I, Im K, Goodrich EL, Bonaca MP, Mosenzon O, Kato ET, Cahn A, Furtado RHM, Bhatt DL, Leiter LA, McGuire DK, Wilding JPH, Sabatine MS. SGLT2 inhibitors for primary and secondary prevention of cardiovascular and renal outcomes in type 2 diabetes: a systematic review and meta-analysis of cardiovascular outcome trials. Lancet. 2019 Jan 5;393(10166):31-39.

14. Salah HM, Al'Aref SJ, Khan MS, Al-Hawwas M, Vallurupalli S, Mehta JL, Mounsey JP, Greene SJ, McGuire DK, Lopes RD, Fudim M. Effect of sodiumglucose cotransporter 2 inhibitors on cardiovascular and kidney outcomes-Systematic review and meta-analysis of randomized placebo-controlled trials. Am Heart J. 2021 Feb;232:10-22.

15. Arnott C, Li Q, Kang A, Neuen BL, Bompoint S, Lam CSP, Rodgers A, Mahaffey KW, Cannon CP, Perkovic V, Jardine MJ, Neal B. Sodium-Glucose Cotransporter 2 Inhibition for the Prevention of Cardiovascular Events in Patients With Type 2 Diabetes Mellitus: A Systematic Review and Meta-Analysis. J Am Heart Assoc. 2020 Feb 4;9(3):e014908.

16. Usman MS, Siddiqi TJ, Memon MM, Khan MS, Rawasia WF, Talha Ayub M, Sreenivasan J, Golzar Y. Sodium-glucose co-transporter 2 inhibitors and cardiovascular outcomes: A systematic review and meta-analysis. Eur J Prev Cardiol. 2018 Mar;25(5):495-502.

17. Zannad F, Ferreira JP, Pocock SJ, Anker SD, Butler J, Filippatos G, Brueckmann M, Ofstad AP, Pfarr E, Jamal W, Packer M. SGLT2 inhibitors in patients with heart failure with reduced ejection fraction: a meta-analysis of the EMPEROR-Reduced and DAPA-HF trials. Lancet. 2020 Sep 19;396(10254):819-829.

18. Chambergo-Michilot D, Tauma-Arrué A, Loli-Guevara S. Effects and safety of SGLT2 inhibitors compared to placebo in patients with heart failure: A systematic review and meta-analysis. Int J Cardiol Heart Vasc. 2020 Dec 11;32:100690.

19. Singh AK, Singh R. Heart failure hospitalization with SGLT-2 inhibitors: a systematic review and meta-analysis of randomized controlled and observational studies. Expert Rev Clin Pharmacol. 2019 Apr;12(4):299-308.

20. Butler J, Usman MS, Khan MS, Greene SJ, Friede T, Vaduganathan M, Filippatos G, Coats AJS, Anker SD. Efficacy and safety of SGLT2 inhibitors in heart failure: systematic review and meta-analysis. ESC Heart Fail. 2020 Dec;7(6):3298-3309.

21. Higgins JP, Altman DG, Gøtzsche PC, Jüni P, Moher D, Oxman AD, Savovic J, Schulz KF, Weeks L, Sterne JA; Cochrane Bias Methods Group; Cochrane Statistical Methods Group. The Cochrane Collaboration's tool for assessing risk of bias in randomised trials. BMJ. 2011 Oct 18;343:d5928.

22. Liberati A, Altman DG, Tetzlaff J, Mulrow C, Gøtzsche PC, loannidis JP, Clarke M, Devereaux PJ, Kleijnen J, Moher D. The PRISMA statement for reporting systematic reviews and meta-analyses of studies that evaluate health care interventions: explanation and elaboration. J Clin Epidemiol. 2009 Oct;62(10):e1-34.

23. DerSimonian R, Laird N. Meta-analysis in clinical trials. Control Clin Trials. 1986 Sep;7(3):177-88.

24. Cinti F, Moffa S, Impronta F, Cefalo CM, Sun VA, Sorice GP, Mezza T, Giaccari A. Spotlight on ertugliflozin and its potential in the treatment of type 2 diabetes: evidence to date. Drug Des Devel Ther. 2017 Oct 3;11:2905-2919.

25. Nassif ME, Windsor SL, Tang F, Khariton Y, Husain M, Inzucchi SE, McGuire DK, Pitt B, Scirica BM, Austin B, Drazner MH, Fong MW, Givertz MM, Gordon RA, Jermyn R, Katz SD, Lamba S, Lanfear DE, LaRue SJ, Lindenfeld J, Malone M, Margulies K, Mentz RJ, Mutharasan RK, Pursley M, Umpierrez G, Kosiborod M. Dapagliflozin Effects on Biomarkers, Symptoms, and Functional Status in Patients With Heart Failure With Reduced Ejection Fraction: The DEFINE-HF Trial. Circulation. 2019 Oct 29;140(18):1463-1476.

26. Damman K, Beusekamp JC, Boorsma EM, Swart HP, Smilde TDJ, Elvan A, van Eck JWM, Heerspink HJL, Voors AA. Randomized, double-blind, placebocontrolled, multicentre pilot study on the effects of empagliflozin on clinical outcomes in patients with acute decompensated heart failure (EMPARESPONSE-AHF). Eur J Heart Fail. 2020 Apr;22(4):713-722.

27. Cannon CP, Pratley R, Dagogo-Jack S, Mancuso J, Huyck S, Masiukiewicz U, Charbonnel B, Frederich R, Gallo S, Cosentino F, Shih WJ, Gantz I, Terra SG, Cherney DZI, McGuire DK; VERTIS CV Investigators. Cardiovascular Outcomes with Ertugliflozin in Type 2 Diabetes. N Engl J Med. 2020 Oct 8;383(15):1425-1435.

Page $7 / 13$ 
28. Bhatt DL, Szarek M, Pitt B, Cannon CP, Leiter LA, McGuire DK, Lewis JB, Riddle MC, Inzucchi SE, Kosiborod MN, Cherney DZI, Dwyer JP, Scirica BM, Bailey CJ, Díaz R, Ray KK, Udell JA, Lopes RD, Lapuerta P, Steg PG; SCORED Investigators. Sotagliflozin in Patients with Diabetes and Chronic Kidney Disease. N Engl J Med. 2021 Jan 14;384(2):129-139.

29. Fitchett D, Zinman B, Wanner C, Lachin JM, Hantel S, Salsali A, Johansen OE, Woerle HJ, Broedl UC, Inzucchi SE; EMPA-REG OUTCOME® trial investigators. Heart failure outcomes with empagliflozin in patients with type 2 diabetes at high cardiovascular risk: results of the EMPA-REG OUTCOME ${ }^{\circ}$ trial. Eur Heart J. 2016 May 14;37(19):1526-34.

30. Empagliflozin reduces the risk of mortality and hospitalization for heart failure across Thrombolysis In Myocardial Infarction Risk Score for Heart Failure in Diabetes categories: Post hoc analysis of the EMPA-REG OUTCOME trial. Diabetes, Obesity and Metabolism. 2020;22(7):1141-1150.

31. Danne T, Biester T, Kordonouri O. Combined SGLT1 and SGLT2 Inhibitors and Their Role in Diabetes Care. Diabetes Technol Ther. 2018 Jun;20(S2):S269S277.

32. Isaji M. SGLT2 inhibitors: molecular design and potential differences in effect. Kidney Int Suppl. 2011 Mar;(120):S14-9.

33. Vrhovac I, Balen Eror D, Klessen D, Burger C, Breljak D, Kraus O, Radović N, Jadrijević S, Aleksic I, Walles T, Sauvant C, Sabolić I, Koepsell H. Localizations of $\mathrm{Na}(+)$-D-glucose cotransporters SGLT1 and SGLT2 in human kidney and of SGLT1 in human small intestine, liver, lung, and heart. Pflugers Arch. 2015 Sep;467(9):1881-98.

34. Sayour AA, Oláh A, Ruppert M, Barta BA, Horváth EM, Benke K, Pólos M, Hartyánszky I, Merkely B, Radovits T. Characterization of left ventricular myocardial sodium-glucose cotransporter 1 expression in patients with end-stage heart failure. Cardiovasc Diabetol. 2020 Sep 30;19(1):159.

\section{Tables}

Table 1. Baseline characteristics of included studies 


\begin{tabular}{|c|c|c|c|c|c|c|c|c|c|c|c|}
\hline Study & $\begin{array}{l}\text { Follow- } \\
\text { up time }\end{array}$ & $\begin{array}{l}\text { Age } \\
\text { (mean) }\end{array}$ & $\begin{array}{l}\text { Female } \\
(\%)\end{array}$ & $\begin{array}{l}\mathrm{DM} \\
(\%)\end{array}$ & $\begin{array}{l}\text { MI } \\
(\%)\end{array}$ & $\begin{array}{l}\text { HF } \\
(\%)\end{array}$ & $\begin{array}{l}\text { NT-pro } \\
\text { BNP } \\
\text { (mean, } \\
\text { pg/mL) }\end{array}$ & $\begin{array}{l}\text { eGFR } \\
\text { (mean, } \\
\mathrm{mL} / \mathrm{min} / 1.73 \mathrm{~m} 2 \text { ) }\end{array}$ & $\begin{array}{l}\text { SBP } \\
\text { (mean, } \\
\text { mmHg) }\end{array}$ & $\begin{array}{l}\text { ACEI/ARB } \\
(\%)\end{array}$ & $\begin{array}{l}\text { ARNI } \\
\text { (\%) }\end{array}$ \\
\hline \multirow{3}{*}{$\begin{array}{l}\text { CANVAS } \\
\text { PROGRAM } \\
\text { (Canagliflozin) }\end{array}$} & \multirow{3}{*}{$\begin{array}{l}188.2 \\
\text { weeks }\end{array}$} & 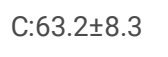 & C:35.1 & C:100 & C:55.8 & C:13.9 & \multirow[t]{3}{*}{ NA } & C: $76.7 \pm 20.3$ & C: $136.4 \pm 15.8$ & Any RAAS in & hibitor \\
\hline & & \multirow[t]{2}{*}{$P: 63.4 \pm 8.2$} & \multirow[t]{2}{*}{ P:36.7 } & \multirow[t]{2}{*}{$P: 100$} & \multirow[t]{2}{*}{ P:57.2 } & \multirow[t]{2}{*}{$P: 15.1$} & & \multirow[t]{2}{*}{ P:76.2 20.8} & \multirow{2}{*}{$\begin{array}{l}\mathrm{P}: \\
136.9 \pm 15.8\end{array}$} & C:80.2 & \\
\hline & & & & & & & & & & P:79.8 & \\
\hline \multirow{2}{*}{$\begin{array}{l}\text { DECLARE-TIMI } \\
58 \\
\text { (Dapagliflozin) }\end{array}$} & \multirow{2}{*}{$\begin{array}{l}4.2 \\
\text { years }\end{array}$} & D:63.9 \pm 6.8 & D:36.9 & D:100 & D:32.9 & D:9.9 & \multirow[t]{2}{*}{ NA } & D:85.4 415.8 & \multirow{2}{*}{$\begin{array}{l}\text { D: } \\
135.1 \pm 15.3 \\
\text { P: } \\
134.8 \pm 15.5\end{array}$} & D:81.3 & \multirow[t]{2}{*}{ NA } \\
\hline & & $P: 64.0 \pm 6.8$ & $P: 27.9$ & P:100 & $\mathrm{P}: 33$ & $P: 10.2$ & & $\mathrm{P}: 85.1 \pm 16.0$ & & $P: 81.3$ & \\
\hline DEFINE-HF & \multirow{2}{*}{$\begin{array}{l}13 \\
\text { weeks }\end{array}$} & $\mathrm{D}: 62.2 \pm 11$ & D:27.5 & D:61.8 & \multirow[t]{2}{*}{ NA } & D:100 & D:1136 & D: $66.9 \pm 21.1$ & \multirow[t]{2}{*}{ NA } & D:58 & D:35.؟ \\
\hline (Dapagliflozin) & & P: $60.4 \pm 12$ & $\mathrm{P}: 25.8$ & $P: 64.4$ & & P:100 & P:1136 & $\mathrm{P}: 71.2 \pm 23.1$ & & P:60.6 & $\mathrm{P}: 28 . \varepsilon$ \\
\hline \multirow{2}{*}{$\begin{array}{l}\text { DAPA-HF } \\
\text { (Dapagliflozin) }\end{array}$} & \multirow{2}{*}{$\begin{array}{l}18.2 \\
\text { months }\end{array}$} & D: $66.2 \pm 11.0$ & D:23.8 & D:41.8 & \multirow[t]{2}{*}{ NA } & D: 100 & D:1428 & D: $66.0 \pm 19.6$ & \multirow{2}{*}{$\begin{array}{l}\text { D: } \\
122.0 \pm 16.3 \\
\text { P: } \\
121.6 \pm 16.3\end{array}$} & D:84.5 & D: 10.5 \\
\hline & & $P: 66.5 \pm 10.8$ & $P: 23.0$ & P:41.8 & & P: 100 & P:1446 & P: $65.5 \pm 19.3$ & & $P: 82.8$ & $\mathrm{P}: 10 . \mathrm{c}$ \\
\hline \multirow{2}{*}{$\begin{array}{l}\text { EMPA-REG } \\
\text { OUTCOME } \\
\text { (Empagliflozin) }\end{array}$} & \multirow{2}{*}{$\begin{array}{l}3.1 \\
\text { years }\end{array}$} & $\begin{array}{l}\text { E: } 63.1 \pm \\
8.6\end{array}$ & $\mathrm{E}: 28.8$ & E: 100 & $\mathrm{E}: 46.7$ & E:9.9 & \multirow[t]{2}{*}{ NA } & E: $74.2 \pm 21.6$ & \multirow{2}{*}{$\begin{array}{l}\text { E: } 135.3 \pm \\
16.9 \\
\text { P: } 135.8 \pm \\
17.2\end{array}$} & $\mathrm{E}: 81$ & \multirow[t]{2}{*}{ NA } \\
\hline & & $\begin{array}{l}\text { P: } 63.2 \pm \\
8.8\end{array}$ & $\mathrm{P}: 28$ & P: 100 & P:46.4 & $P: 10.5$ & & P: $73.8 \pm 21.1$ & & $P: 80.1$ & \\
\hline \multirow{2}{*}{$\begin{array}{l}\text { EMPA- } \\
\text { RESPONSE- } \\
\text { AHF } \\
\text { (Empagliflozin) }\end{array}$} & \multirow{2}{*}{$\begin{array}{l}12 \\
\text { weeks }\end{array}$} & $\mathrm{E}: 79$ & $\mathrm{E}: 40$ & $E: 38$ & $\mathrm{E}: 30$ & $\mathrm{E}: 100$ & E:4406 & $\mathrm{E}: 55 \pm 18$ & E: $127 \pm 22$ & E:45 & E:5 \\
\hline & & P:73 & P:16 & P:28 & P:38 & P:100 & P:6168 & $P: 55 \pm 18$ & P: $121 \pm 25$ & P:50 & $\mathrm{P}: 3$ \\
\hline \multirow{2}{*}{$\begin{array}{l}\text { EMPEROR- } \\
\text { Reduced } \\
\text { (Empagliflozin) }\end{array}$} & \multirow{2}{*}{$\begin{array}{l}16 \\
\text { months }\end{array}$} & $\mathrm{E}: 67.2 \pm 10.8$ & $E: 23.5$ & $E: 49.8$ & NA & $\mathrm{E}: 100$ & E:1887 & $\mathrm{E}: 61.8 \pm 21.7$ & E: & E:70.5 & E:18.3 \\
\hline & & $P: 66.5 \pm 11.2$ & $P: 24.4$ & $P: 49.8$ & & P:100 & P:1926 & $\mathrm{P}: 62.2 \pm 21.5$ & $\begin{array}{l}\text { P: } \\
121.4 \pm 15.4\end{array}$ & P:68.9 & P:20.7 \\
\hline VERTIS-CV & $\begin{array}{l}3.5 \\
\text { vears }\end{array}$ & Er: $64.4 \pm 8.1$ & Er:29.7 & Er: & Er:47.7 & Er:23.4 & NA & Er: $76.1 \pm 20.9$ & 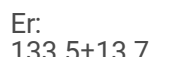 & Er:80.9 & NA \\
\hline (Ertugliflozin) & & $P: 64.4 \pm 8.0$ & $P: 30.7$ & P: 100 & $\mathrm{P}: 48.4$ & $P: 24.5$ & & P: $75.7 \pm 20.8$ & $\begin{array}{l}\text { P: } \\
133.1 \pm 13.9\end{array}$ & P:81.5 & \\
\hline SOLOIST-WHF & 9 & S:69 & S:32.6 & S:100 & NA & S:100 & S:1816.8 & S:49.2 & S:122 & S:82.1 & S:15.Z \\
\hline (Sotagliflozin) & & P:70 & $P: 34.9$ & P:100 & & P:100 & P:1741 & $P: 50.5$ & P:122 & P:83.3 & P:18.2 \\
\hline SCORED & 16 & S:69 & S:44.3 & S:NA & S:19.9 & S:19.9 & S:196 & S:44.4 & S:138 & S:87.5 & S:1.2 \\
\hline (Sotagliflozin) & & P:69 & P:45.5 & P:NA & P:20 & P:19.9 & P:198.1 & $P: 44.7$ & P:139 & P:86.9 & P:1.2 \\
\hline
\end{tabular}

*Any RAAS inhibitor including ACEI/ARB, ARNI and MRA. NT-pro BNP , N- terminal pro-brain natriuretic peptide; eGFR, estimated Glomerular filtration rate; HF, heart failure; DM, diabetes mellitus; SBP, systolic blood pressure; MI, myocardial infarction; ACEl, angiotensin Converting Enzyme Inhibitors; ARB, angiotensin receptor blocker; ARNI, angiotensin receptor-neprilysin inhibitor; MRA, mineralocorticoid receptor antagonist; NA, not applicable (a lack of outcomes reported in the original studies), C, canagliflozin; P, placebo; D, dapagliflozin; E, empagliflozin; Er, ertugliflozin; S, sotagliflozin

Table 2. Subgroup analysis of the individual SGLT2 inhibitors and SGLT2/SGLT1 selectivity in the different cardiovascular outcomes 


\begin{tabular}{|c|c|c|}
\hline & $\begin{array}{l}\text { HF } \\
\text { (study number, } \mathrm{RR}, 95 \% \mathrm{Cl}, R \text { ) }\end{array}$ & $\begin{array}{l}\text { Non-HF } \\
\text { (study number, RR, 95\% } \mathrm{Cl}, R \text { ) }\end{array}$ \\
\hline \multicolumn{3}{|c|}{ Cardiovascular death or hospitalization for heart failure } \\
\hline Dapagliflozin vs placebo & $\mathrm{N}=2,0.79(0.71-0.88, P=0 \%)$ & $\mathrm{N}=1,0.85(0.72-0.99)$ \\
\hline Empagliflozin vs placebo & $\mathrm{N}=2,0.78(0.70-0.88, R=0 \%)$ & $\mathrm{N}=1,0.65(0.53-0.80)$ \\
\hline Canagliflozin vs placebo & $\mathrm{N}=1,0.65(0.51-0.83)$ & $\mathrm{N}=1,0.90(0.75-1.08)$ \\
\hline Ertugliflozin vs placebo & $\mathrm{N}=1,0.87(0.69-1.09)$ & $\mathrm{N}=1,0.94(0.78-1.14)$ \\
\hline Sotagliflozin vs placebo & $\mathrm{N}=2,0.70(0.62-0.79, R=0 \%)$ & $\mathrm{N}=1,0.76(0.42-1.38)$ \\
\hline High SGLT2/SGLT1 selectivity & $\mathrm{N}=5,0.79(0.74-0.85, R=0 \%)$ & $\mathrm{N}=3,0.81(0.66-0.99, P=71 \%)$ \\
\hline Low SGLT2/SGLT1 selectivity & $\mathrm{N}=3,0.69(0.62-0.77, R=0 \%)$ & $\mathrm{N}=2,0.88\left(0.74-1.05, P^{2}=0 \%\right)$ \\
\hline \multicolumn{3}{|l|}{ Cardiovascular death } \\
\hline Dapagliflozin vs placebo & $\mathrm{N}=3,0.87(0.75-1.01, P=0 \%)$ & $\mathrm{N}=1,0.97(0.79-1.19)$ \\
\hline Empagliflozin vs placebo & $\mathrm{N}=1,0.93(0.77-1.12)$ & NA \\
\hline Canagliflozin vs placebo & $\mathrm{N}=1,0.77(0.56-1.06)$ & $\mathrm{N}=1,0.99(0.79-1.24)$ \\
\hline Ertugliflozin vs placebo & NA & NA \\
\hline Sotagliflozin vs placebo & $\mathrm{N}=1,0.89(0.62-1.27)$ & NA \\
\hline High SGLT2/SGLT1 selectivity & $\mathrm{N}=4,0.89(0.79-1.00, R=0 \%)$ & $\mathrm{N}=1,0.97(0.79-1.19)$ \\
\hline Low SGLT2/SGLT1 selectivity & $\mathrm{N}=2,0.82(0.65-1.04, R=0 \%)$ & $\mathrm{N}=1,0.99(0.79-1.24)$ \\
\hline \multicolumn{3}{|l|}{ Hospitalization for heart failure } \\
\hline Dapagliflozin vs placebo & $\mathrm{N}=3,0.75(0.65-0.86, R=0 \%)$ & $N=1,0.73(0.58-0.92)$ \\
\hline Empagliflozin vs placebo & $\mathrm{N}=2,0.72(0.62-0.83, P=0 \%)$ & NA \\
\hline Canagliflozin vs placebo & $\mathrm{N}=1,0.51(0.35-0.75)$ & $\mathrm{N}=1,0.76(0.55-1.04)$ \\
\hline Ertugliflozin vs placebo & NA & NA \\
\hline Sotagliflozin vs placebo & NA & NA \\
\hline High SGLT2/SGLT1 selectivity & $\mathrm{N}=4,0.73(0.66-0.81, R=0 \%)$ & $\mathrm{N}=1,0.73(0.58-0.92)$ \\
\hline Low SGLT2/SGLT1 selectivity & $\mathrm{N}=1,0.51(0.35-0.75)$ & $\mathrm{N}=1,0.76(0.55-1.04)$ \\
\hline
\end{tabular}

$\mathrm{HF}$, heart failure; RR, risk ratio; $\mathrm{Cl}$, confidence interval; $\mathrm{NA}$, not applicable (a lack of outcomes reported in the original studies)

Given that the subgroups included more than two studies, the statistical heterogeneity was assessed using $R$ statistics to quantify the proportion of total outcome variability across the studies.

\section{Figures}




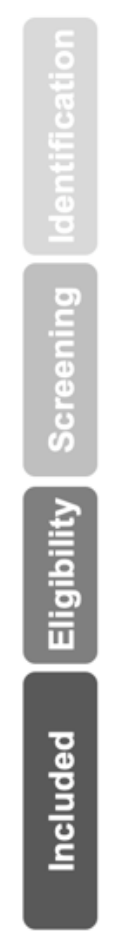

\begin{tabular}{|c|c|}
\hline $\begin{array}{l}\text { Records identified through database } \\
\text { search of PubMed }(n=640) \text {; Cochrane } \\
\text { CENTRAL ( } n=462) ; \text { and Embase } \\
(n=1050)\end{array}$ & \multirow[b]{2}{*}{ Duplicated records excluded $(n=649)$} \\
\hline & \\
\hline $\begin{array}{l}\text { Records after duplicates removed } \\
\qquad(\mathrm{n}=1503)\end{array}$ & \multirow{2}{*}{$\begin{array}{l}1264 \text { Articles excluded: } \\
\text { Did not match research strategy }(n=445) \\
\text { Non-RCTs excluded }(n=819)\end{array}$} \\
\hline \multirow{2}{*}{$\begin{array}{l}\text { Records after primary screening } \\
\qquad(n=239)\end{array}$} & \\
\hline & \multirow{3}{*}{$\begin{array}{l}34 \text { Articles excluded: } \\
21 \text { No full text } \\
11 \text { Did not have published data } \\
2 \text { Study withdrawn }\end{array}$} \\
\hline & \\
\hline $\begin{array}{c}\text { Full-text articles assessed for } \\
\text { eligibility }(n=205)\end{array}$ & \\
\hline & \multirow{3}{*}{$\begin{array}{l}195 \text { Articles excluded: } \\
3 \text { Non-English article } \\
52 \text { Identical articles } \\
20 \text { Protocol } \\
4 \text { Animal studies } \\
116 \text { Did not have separated outcomes of } \\
\text { HF or non-HF patients }\end{array}$} \\
\hline $\begin{array}{l}\text { Studies included in qualitative } \\
\text { synthesis }(n=10)\end{array}$ & \\
\hline Studies & \\
\hline
\end{tabular}

Figure 1

PRISMA flowchart of literature selection. RCTs, randomized controlled trials

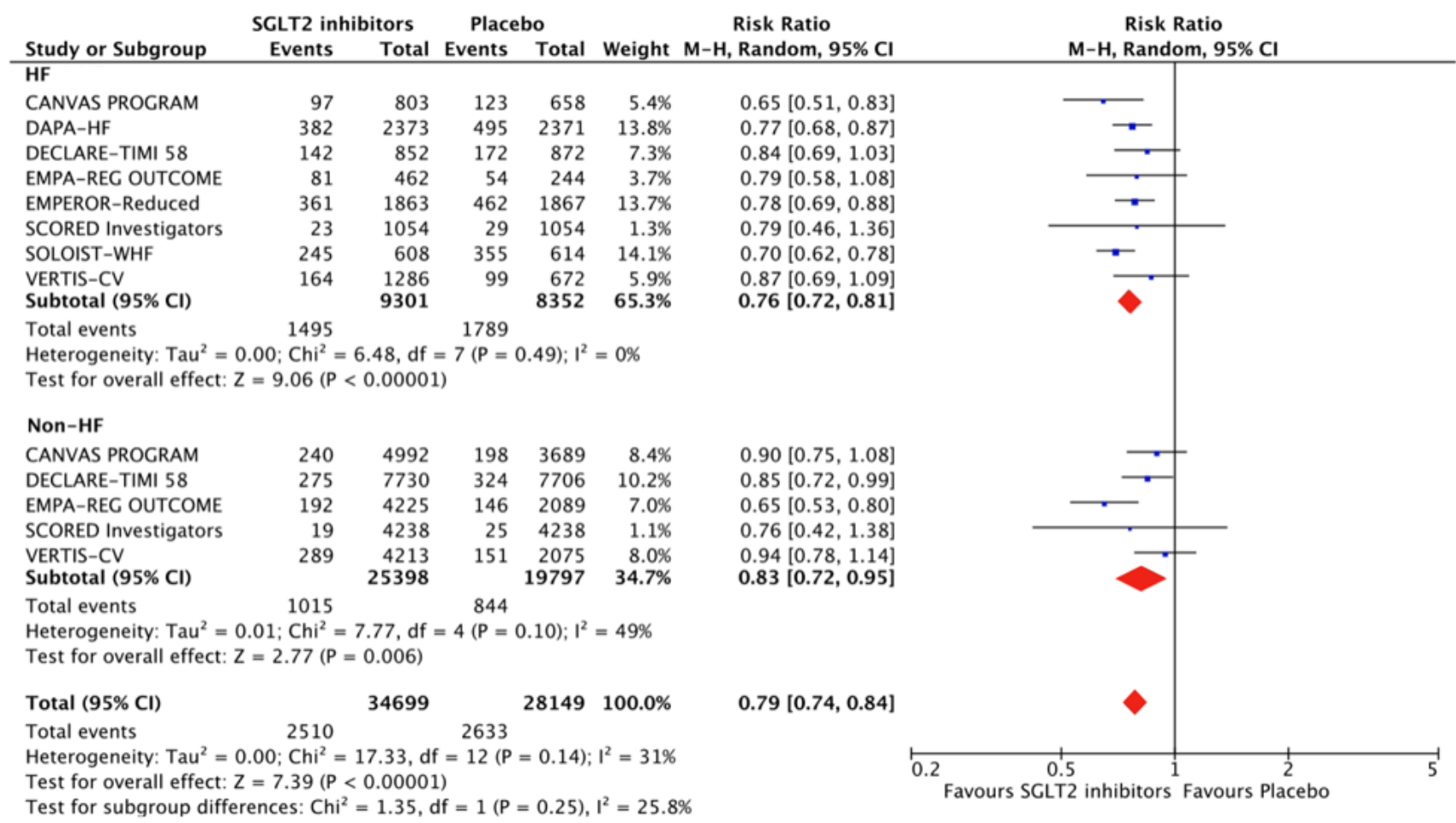

Figure 2

Clinical efficacy of SGLT2 inhibitor in terms of total cardiovascular death or hospitalization for heart failure, stratified by the presence of. heart failure. M-H: Mantel-Haenszel; Cl: confidence interval; HF: heart failure 


\section{(A) Major adverse cardiovascular events}

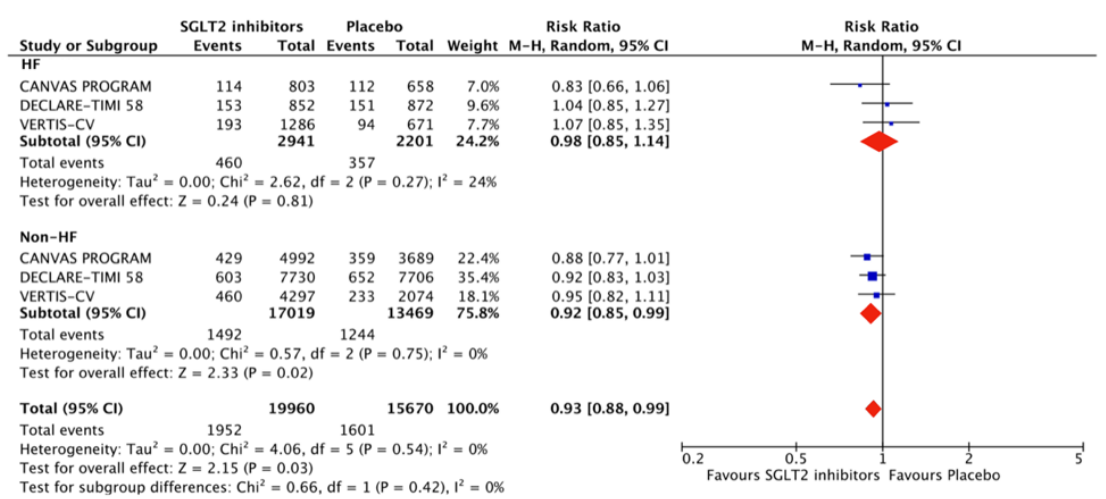

\section{(B) All-cause mortality}

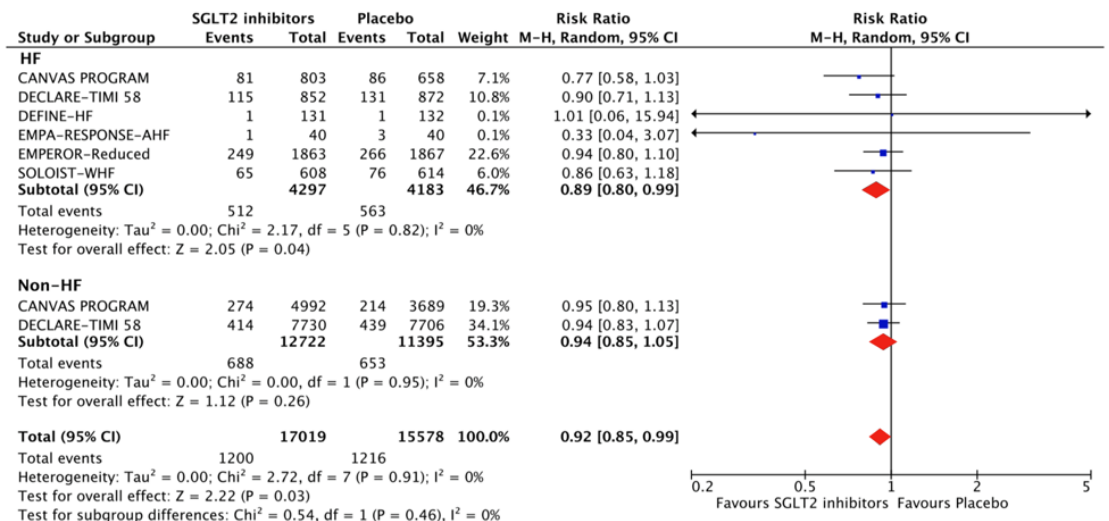

\section{Figure 3}

Clinical efficacy of SGLT2 inhibitors in terms of (A) major adverse cardiovascular events (MACE, composite of myocardial infarction, stroke, and cardiovascular death) and (B) all-cause mortality, stratified by the presence of heart failure. M-H: Mantel-Haenszel; Cl: confidence interval; HF: heart failure 


\section{(A) Cardiovascular death}

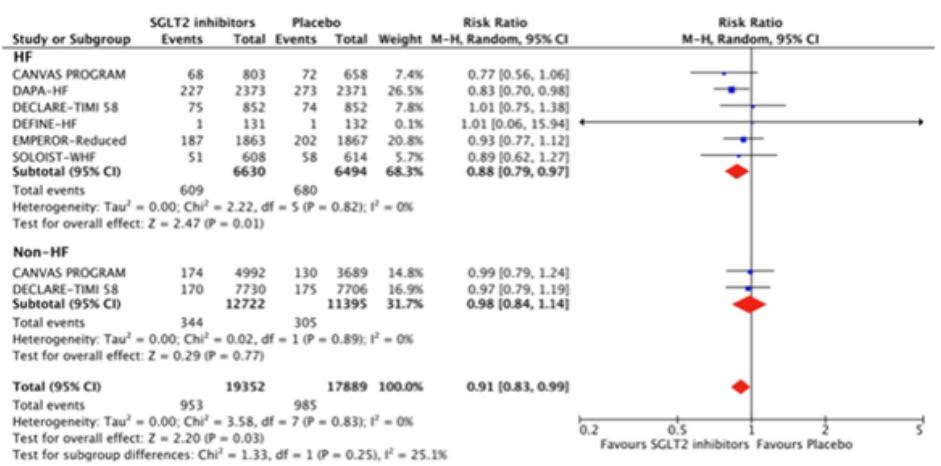

\section{(B) Hospitalization for heart failure}

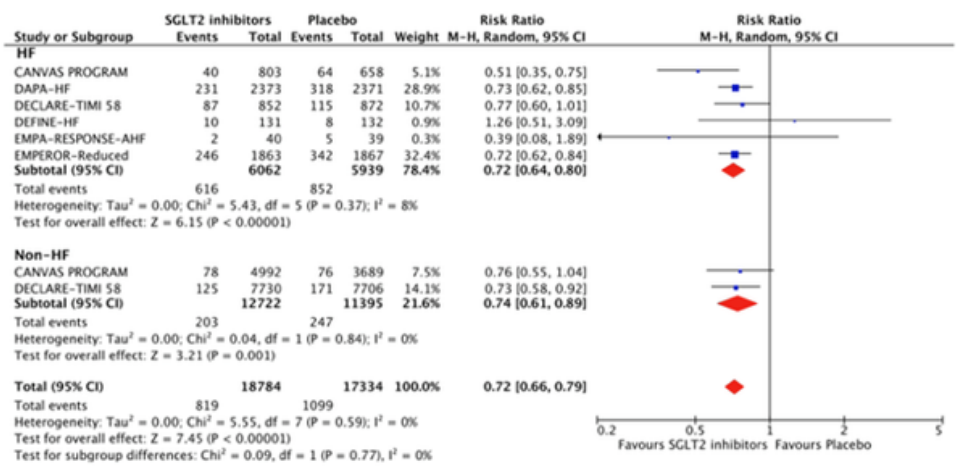

\section{(C) Myocardial infarction}

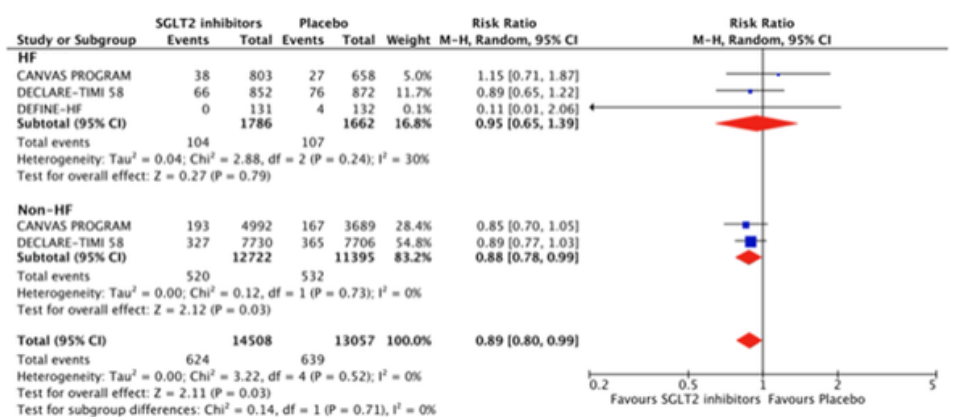

\section{(D) Stroke}

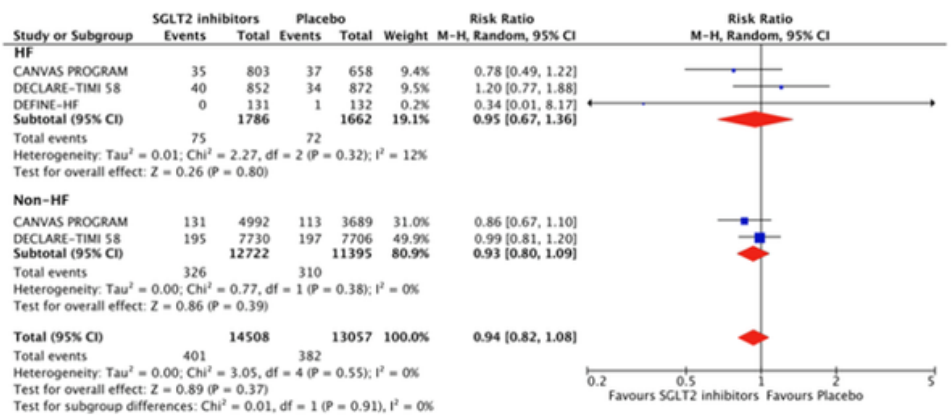

\section{Figure 4}

Clinical efficacy of SGLT2 inhibitors in terms of (A) cardiovascular death, (B) hospitalization for heart failure, (C). myocardial infarction and (D) stroke, stratified by the presence of heart failure. $\mathrm{M}-\mathrm{H}$ : Mantel-Haenszel; $\mathrm{Cl}$ : confidence interval; HF: heart failure

\section{Supplementary Files}

This is a list of supplementary files associated with this preprint. Click to download.

- Supplementarymaterial.docx 